See Article page 161.

\section{Commentary: Diffuse optical spectroscopies: Shedding light on neuroprotective strategies during cardiac surgery}

\author{
Jennifer M. Lynch, MD, PhD, ${ }^{a}$ and \\ Daniel J. Licht, MD
}

In this issue of JTCVS Techniques, Zavriyev and colleagues ${ }^{1}$ investigate the use of diffuse correlation spectroscopy (DCS) and frequency domain near-infrared spectroscopy (FD-NIRS) for quantifying cerebral blood flow and tissue oxygen saturation in adult patients undergoing aortic arch repair procedures requiring hypothermia with circulatory arrest (HCA), retrograde cerebral perfusion (RCP), or antegrade cerebral perfusion (ACP). Among their cohort of 12 adult subjects, 3 underwent RCP, 5 underwent ACP, and 4 underwent HCA. Although this pilot study is too limited by small sample size to enable meaningful conclusions about the superiority of RCP or ACP relative to HCA, it is interesting to note that even in this limited study, a difference between these modalities was observed in the trend of cerebral oxygen saturation and blood flow during the period of circulatory arrest. Specifically, in the pilot data, only ACP was capable of restoring a balance between cerebral oxygen demand and supply during hypothermia. This finding warrants further investigation with a larger study, but even this pilot study demonstrates the importance of

From the ${ }^{\mathrm{a} D e p a r t m e n t}$ of Anesthesiology and Critical Care Medicine, Hospital of the University of Pennsylvania, Philadelphia, Pa; and ${ }^{\mathrm{b}}$ June and Steve Wolfson Laboratory for Clinical and Biomedical Optics, Division of Pediatric Neurology, Children's Hospital of Philadelphia, Philadelphia, Pa.

Disclosures: Dr Licht is supported by grants from the National Institute of Neurological Disorders and Stroke (R01 NS72338, R01 NS060653) and Eunice Kennedy Shriver National Institute of Child Health and Human Development (U01 HD087180-01) and the June and Steve Wolfson Family Foundation. Dr Lynch reported no conflicts of interest.

The Journal policy requires editors and reviewers to disclose conflicts of interest and to decline handling or reviewing manuscripts for which they may have a conflict of interest. The editors and reviewers of this article have no conflicts of interest.

Received for publication Jan 31, 2021; revisions received Jan 31, 2021; accepted for publication Feb 1, 2021; available ahead of print Feb 3, 2021.

Address for reprints: Daniel J. Licht, MD, June and Steve Wolfson Laboratory for Clinical and Biomedical Optics, Colket Translational Research Bldg, 10th floor, Room 10030, 3501 Civic Center Blvd, Philadelphia, PA 19104 (E-mail: licht@ email.chop.edu).

JTCVS Techniques 2021;7:178-9

2666-2507

Copyright $@ 2021$ The Authors. Published by Elsevier Inc. on behalf of The American Association for Thoracic Surgery. This is an open access article under the CC BY-NCND license (http://creativecommons.org/licenses/by-nc-nd/4.0/).

https://doi.org/10.1016/j.xjtc.2021.02.004

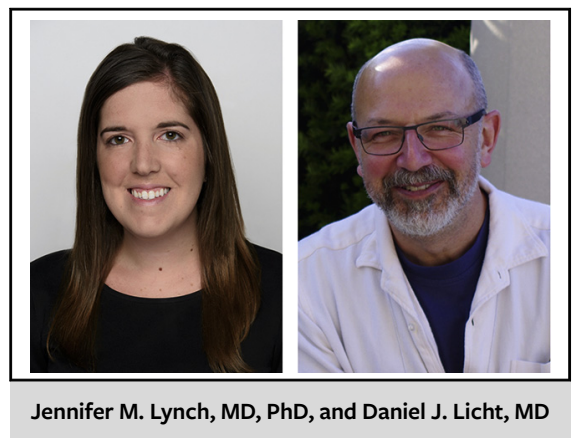

CENTRAL MESSAGE

Noninvasive diffuse optical spectroscopies can fill the need

for cerebral hemodynamic monitoring in cases with hypothermic circulatory arrest.

individualized monitoring of cerebral hemodynamics during cardiac surgery.

The authors demonstrate the feasibility of using novel infrared spectroscopies for continuous, noninvasive quantification of cerebral oxygen metabolism during adult cardiac surgery. The current standard of care for monitoring cerebral tissue health during arch repair requiring circulatory arrest is limited to electroencephalography (EEG) and commercial cerebral oximeters. Although isoelectric activity on EEG is routinely used as an indicator of sufficiently low oxygen demand to allow for interruption of cerebral perfusion, it is not a direct measure of the cerebral tissue oxygen demand. Clinicians also rely on the use of commercial cerebral oximeters to guide decision making in the operating room regarding the safe duration of circulatory arrest. Although these oximeters, like the Medtronic INVOS device used in this study, have been shown to be reliable trend monitors of cerebral oxygenation under normal conditions, they are unable to quantify cerebral oxygen saturation, and rigorous studies have not been done to demonstrate reliability even as trend monitors during hypothermia or periods of low oxygenation and tissue blood volume, such as during HCA.

The FD-NIRS device used by Zavriyev and colleagues is able to accurately quantify cerebral oxygen saturation and is reliable even during $\mathrm{HCA}$, because the technique does not rely on assumptions of tissue optical properties, which may be altered during HCA. Used together, FD-NIRS and DCS offer a way to noninvasively quantify cerebral oxygen metabolism during the perioperative period in this patient population. $^{2-4}$ In the operating room, this technology has 
the potential to aid in the determination of the adequacy of cerebral perfusion during HCA, RCP, or ACP. As pointed out by the authors, the adequacy of cerebral perfusion from ACP or RCP is dependent on the patient's anatomy (eg, patent circle of Willis), so the ability to individualize this care is crucial in neuroprotective efforts.

\section{References}

1. Zavriyev AI, Kaya K, Farzam P, Farzam PY, Sunwoo J, Jassar AS, et al. The role of diffuse correlation spectroscopy and frequency-domain near-infrared spectroscopy in monitoring cerebral hemodynamics during hypothermic circulatory arrests. J Thorac Cardiovasc Surg Tech. 2021;7:161-77.

2. Buckley EM, Lynch JM, Goff DA, Schwab PJ, Baker WB, Durduran T, et al. Early postoperative changes in cerebral oxygen metabolism following neonatal cardiac surgery: effects of surgical duration. J Thorac Cardiovasc Surg. 2013;145: 196-205.

3. Lynch JM, Ko T, Busch DR, Newland JJ, Winters ME, Mensah-Brown K, et al Preoperative cerebral hemodynamics from birth to surgery in neonates with critical congenital heart disease. J Thorac Cardiovasc Surg. 2018;156:1657-64.

4. Jain V, Buckley EM, Licht DJ, Lynch JM, Schwab PJ, Naim MY, et al. Cerebral oxygen metabolism in neonates with congenital heart disease quantified by MRI and optics. J Cereb Blood Flow Metab. 2014;34:380-8. 